\title{
INTERFACIAL STRESS OF STEEL BEAMS STRENGTHENED WITH PRESTRESSED CFRP LAMINATE AND MECHANICAL ANCHORAGE.
}

\author{
Moahmed A. Gharib ${ }^{1}$, Ezzeldin Y. Sayed-Ahmed ${ }^{1}$ and Mohamed A. Khedr ${ }^{2}$ \\ ${ }^{1}$ Structural Eng. Dept, Ain Shams University, Egypt \\ ${ }^{2}$ Dept. of Civil Eng., Faculty of Eng., Benha University \\ تز ايد في السنوات الأخيرة استخدام ألواح المواد المركبة المقو اة بالكربون في إصلاح وتقوية المنشآت الخرسانبة

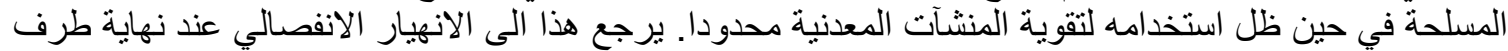

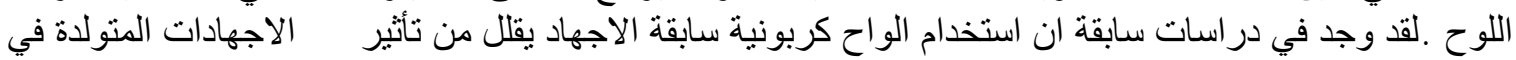

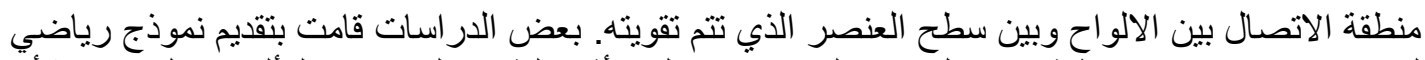

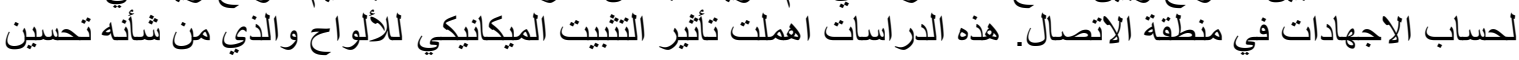

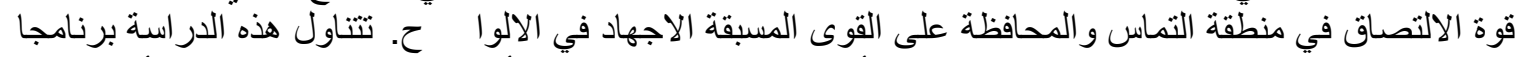

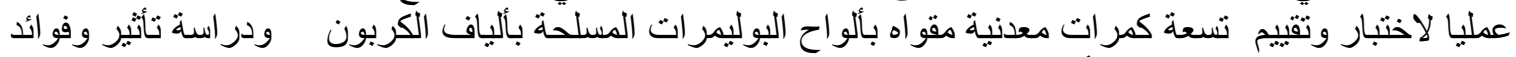

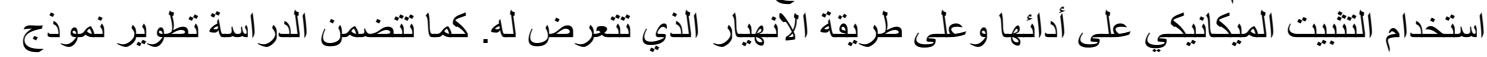

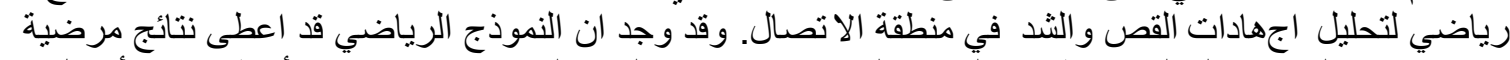

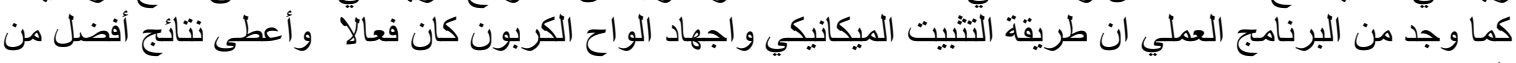 \\ التقوية بدونهم.
}

\begin{abstract}
Strengthening substandard steel beams using Carbon Fiber Reinforced Polymer (CFRP) may be limited by the premature failure caused by debonding in the adhesive layer commonly used to attach the CFRP to the steel beam. Prestressing the (CFRP) laminates is a technique that can improve the effectiveness of such strengthening method and improve both the strength and serviceability behavior of steel beams by increasing the overall member stiffness. Previous studies introduced analytical models to predict the stresses distribution over the contact area between the (CFRP) laminate and the steel beam. However, such studies did not consider the importance of using mechanical anchorage which was found essential to maintain the prestressing force in the (CFRP) laminate. In this study, an analytical model is presented to predict the shear and normal stresses affecting the adhesive layer of steel I-beams subjected to flexural two point loads and strengthened with prestressed CFRP laminate when mechanical anchorage system is used. The equations were employed to calculate the stress on beams tested in an experimental program carried out to evaluate the performance of the proposed strengthening system.
\end{abstract}

KEYWORDS: CFRP Laminate, Adhesive, Mechanical Anchorage, Prestressing. 


\section{INTRODUCTION}

Using CFRP strips in retrofitting and strengthening substandard steel structures is as commonly as its usage for concrete structure [1]. This strengthening method usually consists of CFRP layer which typically is attached to the substandard steel beam lower flange using a layer of adhesive [2 \& 3]. The drawback of using such a procedure is the premature failure of the steel - CFRP hybrid section due to the debonding failure of the adhesive layer. Some studies have introduced prestressing to the CFRP laminates as a solution to debonding issue and to fully utilize the strengthened section. It is found that prestressing has a positive effect on delaying the debonding premature failure [2]. Previous studies highlighted the importance of applying pretension force to the CFRP laminates [4]. Several techniques can be used to apply the pretension force to the CFRP but none of these techniques can be effective without using mechanical anchorage because of the debonding. Adding mechanical anchorage at both ends of the laminate can ensure more ductile behavior also increasing the allowable level of prestressing that can be applied. Researchers found that the use of a mechanical anchorage can result in a great improvement in serviceability and strength [2 \& 6]. Some studies proposed an analytical model to calculate the shear and normal stress developed in the contact zone between the steel surface and the CFRP layer attached to it [7, 8, $9 \& 10]$. However, the presence and the effect of using mechanical anchorage was not considered. In this study, an analytical model to predict the shear and normal stress affecting the adhesive layer in a prestressed CFRP system with mechanical anchorage for strengthening steel beams under flexural loading is introduced. The results obtained from the analysis is compared to the results obtained from the experimental program which was carried out in King Abdulaziz University (2014) to investigate the effectiveness and the feasibility of that system.

\section{THE EXPERIMENTAL PROGRAM}

A total of nine steel beams strengthened with different configurations of prestressed CFRP laminate were tested in flexure under static loading up to failure.

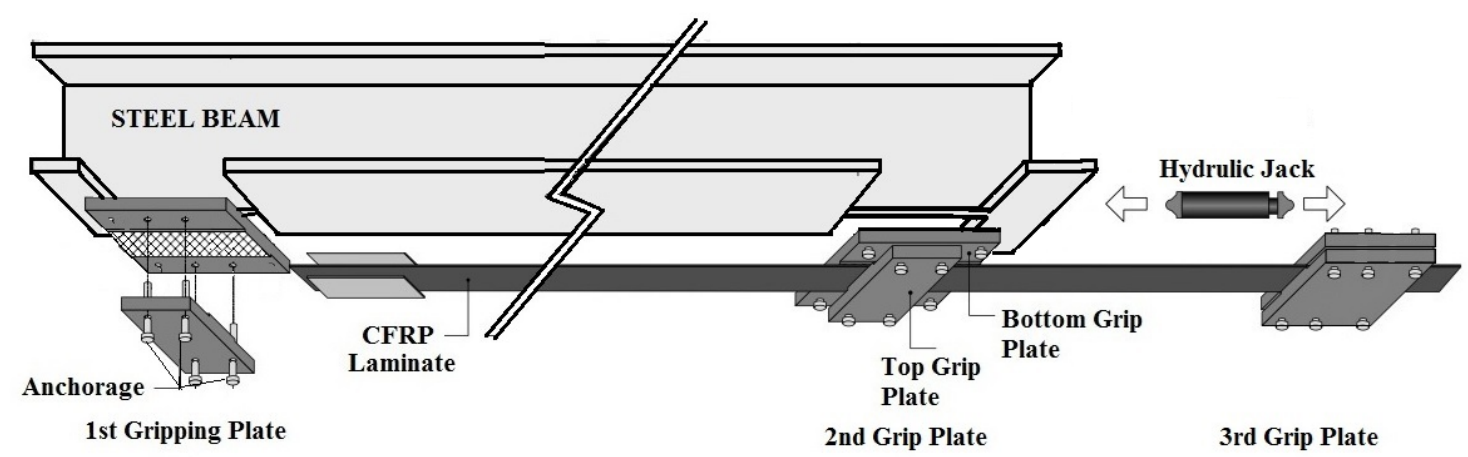

Fig. 1. Pretension system adopted for all beams strengthened with CFRP prestressed laminate.

The main parameters considered in the experimental program are the prestressing levels, the yield strength of the steel beam and the presence or absence of the mechanical anchorage at both ends of the CFRP laminate. A simple jacking system configuration as shown in Figures (1) to (3) is used. 


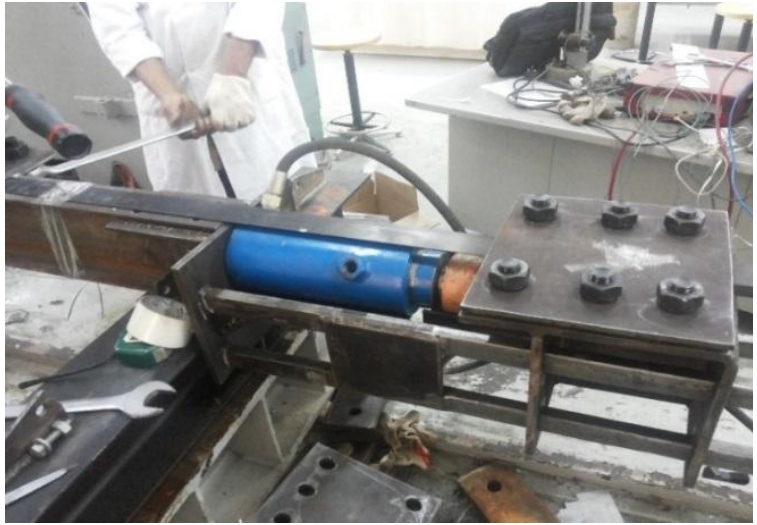

Figure 2. Applying pre-tension force.

\subsection{Description of the Beams}

IPE 160 /

W $6 \times 20$

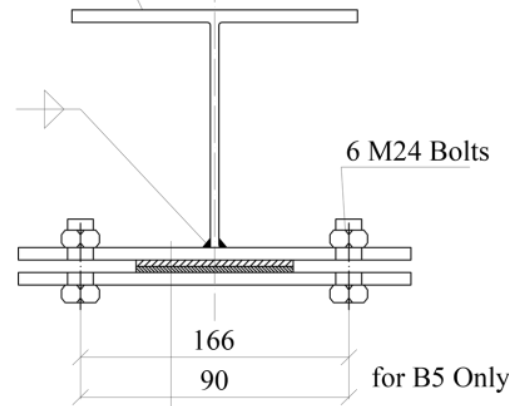

Bottom Gripping Plate $16 \mathrm{~mm}$

$1 \mathrm{~mm}$ Adhesive Layer

1.2mm CFRP Laminate

Top Gripping Plate $16 \mathrm{~mm}$

Figure 3. Strengthened steel beam's cross-section at the location of the gripping plates.

The details of the experimental program are given in Table (1). The section of the 1st beam tested is IPE160. The other eight beams have a cross-section of W6x20. The total length of each of the nine steel beams is $2,900 \mathrm{~mm}$. The yield strength of the steel beams is shown in Table (2). Specimen CB1 and CB1A are the control specimens which with no CFRP strips. Specimen CB2 is strengthened with bonded CFRP which is not prestressed.

Table 1. Test Specimen Details.

\begin{tabular}{cccc}
\hline Specimen & $\begin{array}{c}\text { CFRP lami- } \\
\text { nate }\end{array}$ & Anchorage & $\begin{array}{c}\text { Pretension } \\
\text { Force }\end{array}$ \\
\hline TB & $50 \times 1.2 \mathrm{~mm}$ & Yes & Yes \\
CB1 & No & No & No \\
CB1A & No & No & No \\
CB2 & $100 \times 1.2 \mathrm{~mm}$ & No & No \\
B1-25-NA & $100 \times 1.2 \mathrm{~mm}$ & No & $25 \mathrm{kN}$ \\
B2-45-NA & $100 \times 1.2 \mathrm{~mm}$ & No & $45 \mathrm{kN}$ \\
B3-25-AN & $100 \times 1.2 \mathrm{~mm}$ & Yes & $25 \mathrm{kN}$ \\
B4-45-AN & $100 \times 1.2 \mathrm{~mm}$ & Yes & $45 \mathrm{kN}$ \\
B5-25-AN & $50 \times 1.2 \mathrm{~mm}$ & Yes & $25 \mathrm{kN}$ \\
\hline
\end{tabular}

All other specimens (Table 1) are strengthened with CFRP strips which are prestressed to different levels with/without end mechanical anchorage. The pretension levels in the CFRP strips are either $25 \mathrm{kN}$ or $45 \mathrm{kN}$. The width of the CFRP laminate is $100 \mathrm{~mm}$ except for Specimens TB and B5-25-AN where the width is $50 \mathrm{~mm}$. Figure (3) shows the beam cross section and the CFRP reinforcement. To prevent the local buckling of the beams web, vertical stiffeners are added to all beams above the supports and below the load application points. The beams are also laterally restrained to prevent lateral torsional flexure buckling except for specimen (TB).

\subsection{Material Properties}

The mechanical properties of the steel beam and CFRP are obtained from both material testing and manufacture data sheet. The measured material properties of the steel beam are shown in Table (2). The mechanical properties of the CFRP laminate are obtained from the manufacturer data sheet and presented in Table (3). Epoxy adhesive is used to bond the CFRP laminate to the surface of the steel beam. The average mechanical properties of the adhesive are shown in Table (4). 
Table 2. Mechanical properties of the analyzed beams.

\begin{tabular}{ccc}
\hline Specimen & $\begin{array}{c}\text { Yield Stress } \\
(\mathrm{MPa})\end{array}$ & $\begin{array}{c}\text { Tensile Strength } \\
(\mathrm{MPa})\end{array}$ \\
\hline TB & 380 & 450 \\
\hline CB1 & 390 & 560 \\
\hline CB1A & 350 & 520 \\
\hline CB2 & 390 & 560 \\
\hline B1-25-NA & 390 & 560 \\
\hline B2-45-NA & 390 & 560 \\
\hline B3-25-AN & 390 & 560 \\
\hline B4-45-AN & 350 & 520 \\
\hline B5-25-AN & 390 & 560 \\
\hline
\end{tabular}

Table 3. Properties of the CFRP laminate.

\begin{tabular}{lc}
\hline $\begin{array}{c}\text { Mechanical proper- } \\
\text { ties }\end{array}$ & Value (MPa) \\
\hline Tensile modulus & 165,000 \\
\hline Tensile strength & 3,100 \\
\hline
\end{tabular}

\subsection{Test Set-up}

The beams are simply supported and subjected to two points loading as shown in Figure (4). The load was applied incrementally to the beam using a universal testing machine.

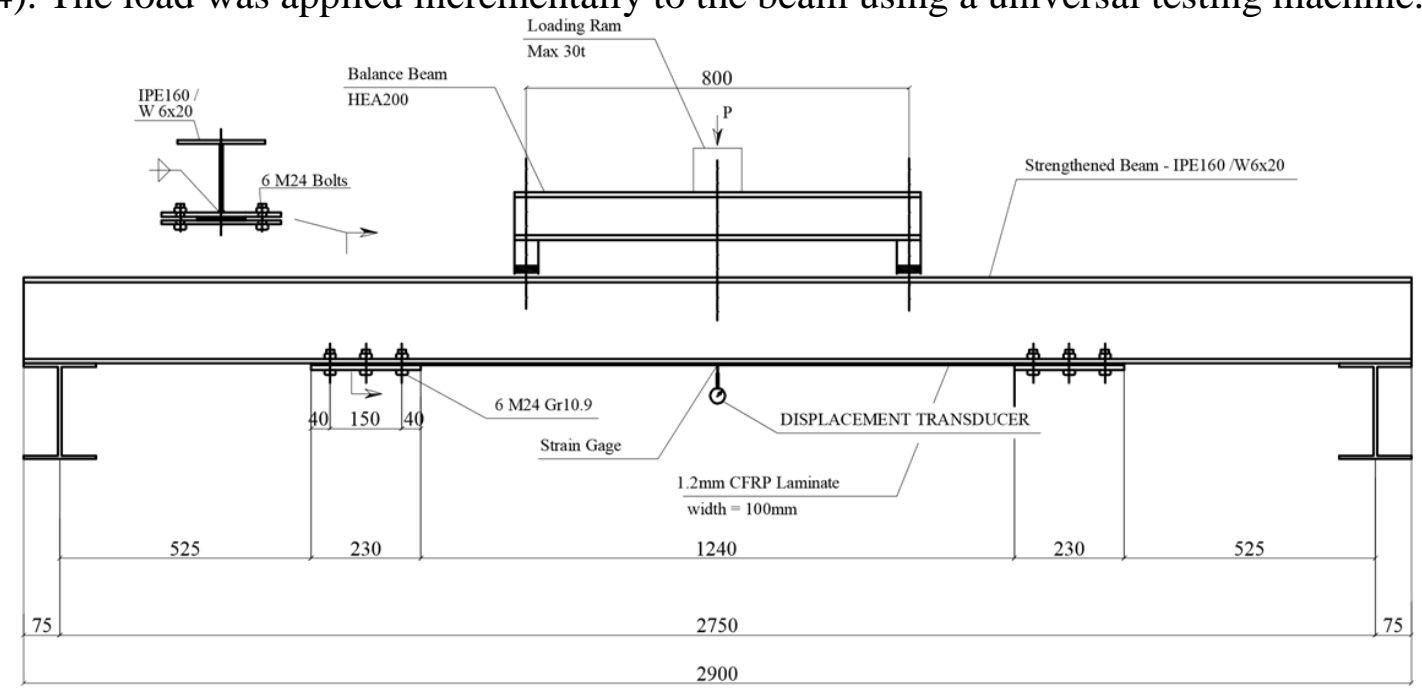

Fig. 4. Test Setup for a typical strengthened beam

\section{EXPERIMENTAL RESULTS}

\subsection{Failure Modes}

Generally, prestressing the CFRP laminate reduced the deflection and delayed the premature debonding failure. Both the reduction of the deflection and the delay in debonding were proportion to the level of the laminate prestress. The control beams CB-1 and $\mathrm{CB}-1 \mathrm{~A}$ failed in a typical flexural manner. Failure of the beam strengthened with nonprestressed CFRP laminate CB-2 started by the debonding of the laminate with a $1.2 \%$ slight increase in the failure load. The CFRP- prestressed beams without end anchorage B1-25-NA and B2-45-NA failed by debonding of the CFRP laminate from the steel bottom flange which took place immediately after releasing the grip anchor at both ends of the beam. The debonding started at the ends of the CFRP laminate which remained attached along the middle part of the beam. Final failure took place with total debonding of the laminate with a slight increase in the failure load. 
Table 5. Results of the experimental investigation .

\begin{tabular}{|c|c|c|c|c|c|c|c|}
\hline \multirow[b]{2}{*}{ Beam No. } & \multirow{2}{*}{$\begin{array}{c}\text { CFRP } \\
\text { Jacking } \\
\text { Strain } \\
(\mu \varepsilon)\end{array}$} & \multirow[b]{2}{*}{$\begin{array}{c}\text { Yield } \\
\text { Load } \\
P_{y}(\mathrm{kN})\end{array}$} & \multicolumn{2}{|c|}{ CFRP debonding load } & \multicolumn{2}{|c|}{ CFRP rupture load } & \multirow[b]{2}{*}{$\begin{array}{l}\text { CFRP } \\
\text { Failure }\end{array}$} \\
\hline & & & $P_{d e}(\mathrm{kN})$ & $\begin{array}{l}\text { Associated } \\
\text { Strain }(\mu \varepsilon)\end{array}$ & $P_{f r u}(\mathrm{kN})$ & $\begin{array}{l}\text { Associated } \\
\text { Strain }(\mu \varepsilon)\end{array}$ & \\
\hline TB & 3050 & 108.1 & No debonding & No debonding & No Rupture & No Rupture & No Failure \\
\hline $\mathrm{CB}$ & - & 172.7 & N/A & N/A & N/A & N/A & N/A \\
\hline CB1A & - & 161.0 & N/A & N/A & N/A & N/A & N/A \\
\hline CB2 & - & 174.8 & 193.2 & 5290 & No Rupture & No Rupture & Debonding \\
\hline B1-25-NA & 3092 & N/A & 64.8 & 15.16 & No Rupture & No Rupture & Debonding \\
\hline B2-45-NA & 4021 & N/A & 76.33 & 16.48 & No Rupture & No Rupture & Debonding \\
\hline B3-25-AN & 3140 & 193.0 & 204.5 & 3953 & 199.7 & 4435 & Rupture \\
\hline B4-45-AN & 3984 & 166.3 & 178.9 & 5725 & 190.5 & 9601 & Rupture \\
\hline B5-25-AN & 3103 & 195.2 & No debonding & No debonding & 202.3 & 12101 & Rupture \\
\hline
\end{tabular}

The CFRP-prestressed beams B3-25-AN and B5-25-AN with end anchorage and Fy $=390 \mathrm{MPa}$ failed in a typical flexural manner. The CFRP laminate experienced a sudden rupture failure with a considerable increase in the failure load of $12 \%$ to $13 \%$ respectively compared to the non-strengthened control beam CB-1. Both these beams developed a full plastic hinge at failure after CFRP rupture without encountering any premature debonding failure. The same failure mode was also recorded for beam CFRPprestressed beams B4-45-AN (Fy $=350 \mathrm{MPa})$ with end anchorage, but the achieved strength enhancement was $3.3 \%$ in yield load which is lower than the previous beams. The results of the experimental investigation are summarized in Table (5).

\section{PROPOSED ANALYTICAL MODEL AND THEORETICAL AP- PROACH}

The debonding failure mode is caused by interfacial stress concentration in the contact surface in the end zone. Closed-form solutions of such stresses are thus essential in developing any design guidelines for strengthening beams with bonded prestressing CFRP laminates. Consider a steel beam with a typical I - section strengthened with a prestressed laminate bonded to the tension face as shown in Figure (5). in this analysis the following assumptions are made:

- All materials are assumed to follow linear elastic behaviour.

-Stiffness of the steel beam is much greater than the stiffness of the CFRP laminate.

-Plane section remains plane After deformation

-Bending deformations of the adhesive can be neglected

-No slip will occur at the interface area before failure take place.

-Constant stresses through the thin adhesive layer thickness.

Figure (5) shows a schematic sketch of a beam strengthened with a bonded prestressed laminate where $P_{l}$ is the residual prestressing force in the laminate. The loss of prestressing force in the laminates is

$\Delta P_{l}=P_{0}-P_{l}$

However, in case of using a well fastened mechanical anchorage and applying proper adhesive layer, the loss of the prestressing $P_{l}$ force can be neglected and it can be assumed that $P_{l}=P_{0}$, hence the prestressing force in the steel beam $P_{s}$ can be expressed as below:

$P_{S}=-P_{l}$ 


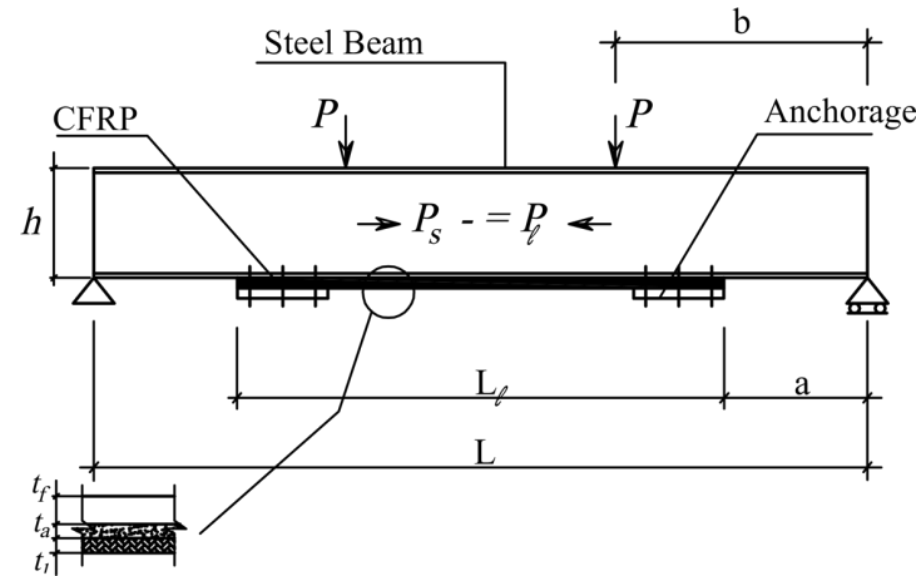

Fig. 5. Schematic sketch of analyzed Beam.

A differential segment of a plated beam is shown in Figure (6), where the interfacial shear and normal stresses are denoted by $\tau(x)$ and $\sigma(x)$, respectively. Figure (6) also shows the positive sign convention for the bending moment, shear force, axial force and applied loading.

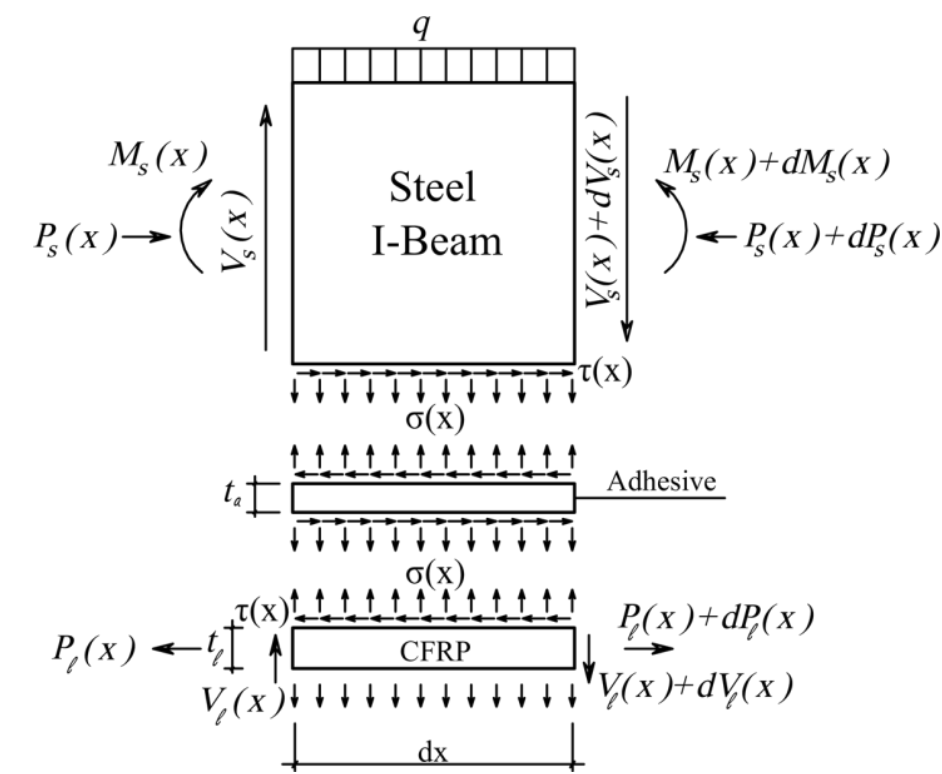

Fig. 6. Finite element of a strengthened beam with acting forces.

\subsection{Adhesive Shear Stress}

Shear stress in the adhesive layer is directly related to the difference in deformation between the laminate and lower flange of the steel beam:

$$
\tau(x)=\frac{G_{a}}{t_{a}}\left[u_{l}(x)-u_{s}(x)\right]
$$

where $G_{a}$ is the adhesive shear modulus, $t_{a}$ is the thickness of the adhesive layer, $u_{l}$ and $u_{s}$ denote the displacement of the steel beam at the bottom of lower flange, and the displacement of the externally bonded prestressed laminate at the boundary of the bond, respectively. Equation (3) can be expressed in terms of the mechanical strain of the steel beam, $\varepsilon_{s}(x)$, and the prestressed laminate $\varepsilon_{l}(x)$ after differentiating the equation with respect to $x$, since tensile strain at the bottom of the beam is induced by two basic stress components: (1) the tensile stress induced by the bending moment $M_{s}(x)$ in the beam and (2) the axial stress induced by the adhesive shear stress at the bond interface. 
$\frac{d \tau(x)}{d x}=\frac{G_{a}}{t_{a}}\left[\varepsilon_{l}(x)-\left(\frac{M_{s}(x) h}{2 E_{s} I_{s}}-\frac{P_{s}(x)}{E_{s} A_{s}}\right)\right]$

Where $A_{s}$ is the steel beam cross-sectional area, $I_{s}$ is the second moment of area of the steel beam, $E_{s}$ is the modulus of elasticity of the steel beam, $t_{l}$ is the thickness of the CFRP laminate, $b_{l}$ is the width of the CFRP laminate and $E_{l}$ is the tensile modulus of the CFRP laminate. Strain in the laminate can be expressed as:

$\varepsilon_{l}(x)=A_{11}^{x} \frac{N_{x}}{b_{l}}$

Where $A_{11}^{x}=\frac{b_{l}}{A_{l} E_{l}}$ which is the extensional matrix component in the laminate overall stiffness matrix and $N_{x}=P_{l}$ since the axial load in the beam's longitudinal axis is the only load considered. Substitute in Equation (4) and obtain second derivative:

$$
\frac{d^{2} \tau(x)}{d x^{2}}=\frac{G_{a}}{t_{a}}\left[\frac{A_{11}^{x} d P_{l}(x)}{b_{l} d x}-\frac{d P_{s}(x)}{E_{s} A_{s} d x}-\frac{h}{2 E_{s} I_{s}} \frac{d M_{s}(x)}{d x}\right]
$$

From equilibrium of segment shown in Figure (7) the following relations can be obtained:

$$
\frac{d P_{s}(x)}{d x}=b_{l} \tau(x), \frac{d P_{l}(x)}{d x}=-b_{l} \tau(x) \& \frac{d M_{s}(x)}{d x}=V_{s}(x)-b_{l} \frac{h}{2} \tau(x)
$$

Substituting in Equation (6), the general solution of the resulted deferential equation is

$$
\tau(x)=B_{1} \cosh (\lambda x)+B_{2} \sinh (\lambda x)+\frac{G_{a} h}{2 E_{s} I_{s} t_{a} \lambda^{2}} V_{s}(x)
$$

Where

$$
\lambda^{2}=\frac{G_{a}}{t_{a}}\left[A_{11}^{x}+\frac{b_{l}}{E_{s} A_{s}}+\frac{h^{2} b_{l}}{4 E_{s} I_{s}}\right]
$$

And $B_{1}$ and $B_{2}$ are the deferential equation constants. For the case of two point loads where the distance from end of laminate to the end of the beam $(a)$ is smaller than the distance from the point load to the end of the beam $(b)$, the adhesive shear stress can be calculated on two intervals:

1st Interval: for $0 \leq x \leq(b-a)$, at this interval based on Equation (8), the general solution for the interfacial shear stress considering value of $V_{s}=P$ is

$\tau_{1}(x)=B_{1} \cosh (\lambda x)+B_{2} \sinh (\lambda x)+m_{1} P$

Where

$$
m_{1}=\frac{G_{a} h}{2 E_{s} I_{s} t_{a} \lambda^{2}}
$$

2nd Interval: for $(b-a) \leq x \leq L_{l}$, at this interval, the general solution for the interfacial shear stress

$$
\tau_{2}(x)=B_{3} \cosh (\lambda x)+B_{4} \sinh (\lambda x)
$$

To solve Equations (10) \& (11), the boundary conditions are:

1st boundary condition: based on the symmetry of the structure, the displacement at middle of the structure is zero. Therefore, at $x=L_{l} / 2$,

$$
\tau\left(\frac{L_{l}}{2}\right)=u_{l}\left(\frac{L_{l}}{2}\right)=u_{s}\left(\frac{L_{l}}{2}\right)=0
$$


Substitute in Equation (11), this will result that

$B_{3}=-B_{4}$

2nd boundary condition: at $x=(b-a), \tau(x)$ is continuous, this means that $\tau_{1}(b-a)=\tau_{2}(b-a)$

3rd boundary condition: at $x=(b-a), \frac{d \tau(x)}{d x}$ is continues so $\frac{d \tau_{1}(b-a)}{d x}=\frac{d \tau_{2}(b-a)}{d x}$

This two boundary condition require continuity of the interfacial shear stress and its first derivative under the point load. Substitute in Equations (10) \& (11) gives the interfacial shear stress equations:

$\tau_{1}(x)=-B_{2} e^{-\lambda x}+m_{1} P x$

and

$\tau_{2}(x)=-B_{3} e^{-\lambda x}$

4th boundary condition: at the end of the laminate due to the presence of the mechanical anchorage

At $x=0, P_{l}(0)=-P_{s}(0)=P_{0}$ and $M_{s}(0)=P a$, by substituting in Equation (4) and equating the result to the $1^{\text {st }}$ derivative of Equations (14) \& (15) the value of $B_{2}$ and $B_{3}$ can be detrained

$B_{2}=\frac{G_{a}}{\lambda t_{a}}\left[\left(\frac{A_{11}^{x}}{b_{l}}+\frac{1}{E_{s} A_{s}}\right) P_{0}-\frac{P a h}{2 E_{s} I_{s}}\right]+\frac{m_{1}}{\lambda} P$

and

$$
B_{3}=\frac{G_{a}}{\lambda t_{a}}\left[\left(\frac{A_{11}^{x}}{b_{l}}+\frac{1}{E_{s} A_{s}}\right) P_{0}-\frac{P a h}{2 E_{s} I_{s}}\right]+\frac{m_{1}}{\sinh \lambda(b-a)} P
$$

\subsection{Adhesive Normal Stress}

Analyzing the adhesive segment after loading the beam, vertical separation occurs between the steel beam and CFRP lamina. This delamination creates an interfacial normal stress acting on the adhesive layer. The normal stress, $\sigma(x)$, can be calculated as:

$$
\sigma(x)=\frac{E_{a}}{t_{a}}\left[v_{l}(x)-v_{s}(x)\right]
$$

Where $v_{l}(x)$ and $v_{s}(x)$ are the vertical displacements of laminate and steel beam, respectively. $E_{\pi}$ is the Young's modulus of adhesive material. From equilibrium in Figure (6) of steel beam and laminate, and after neglecting second-order terms, following relationships can be obtained for the Steel beam:

$$
\frac{d V_{s}(x)}{d x}=-q-b_{l} \sigma(x), \frac{d^{2} v_{s}(x)}{d x^{2}}=\frac{-M_{s}(x)}{E_{s} I_{s}} \text { and } \frac{d M_{s}(x)}{d x}=V_{s}(x)-\tau(x) b_{l} \frac{h}{2}
$$

For the CFRP laminate:

$$
\begin{aligned}
& \frac{d M_{l}(x)}{d x}=V_{l}(x)-\tau(x) b_{l} \frac{t_{l}}{2}, \frac{d V_{l}(x)}{d x}=b_{l} \sigma(x) \\
& \frac{d^{2} v_{l}(x)}{d x^{2}}=\frac{-D_{11}^{x}}{b_{l}} M_{l}(x)
\end{aligned}
$$

Where $D_{11}^{x}$ is the laminate flexural stiffness matrix and for simplification it can be considered $D_{11}^{x}=\frac{12}{t_{l}^{3} E_{l}}$ for symmetric unidirectional laminate 
The governing differential equations for the deflections of steel beam and laminate based on the equilibrium, can be expressed in terms of the interfacial shear and normal stresses for the Steel beam and the CFRP laminate respectively as follows:

$$
\frac{d^{4} v_{s}(x)}{d x^{4}}=\frac{1}{E_{s} I_{s}} b_{l} \sigma(x)+\frac{h}{2 E_{s} I_{s}} b_{l} \frac{d \tau(x)}{d x}+\frac{1}{E_{s} I_{s}} q \text { and } \frac{d^{4} v_{l}(x)}{d x^{4}}=-D_{11}^{x} \sigma(x)+D_{11}^{x} \frac{t_{l}}{2} \frac{d \tau(x)}{d x}
$$

The governing differential equations of the interfacial normal stress can be expressed by substitution of Equation (22) into the fourth derivation of Equation (18) gives the governing differential equation for the interfacial normal stress. The general solution for the resulted expression (based on the assumption that all normal stress on the adhesive layer tends to zero) is

$$
\sigma(x)=e^{-\beta x}\left[C_{1} \cos (\beta x)+C_{2} \sin (\beta x)\right]-n_{1} \frac{d \tau(x)}{d x}-n_{2} P
$$

Where:

$$
\begin{aligned}
& \beta=\sqrt[4]{\frac{E_{a}}{4 t_{a}}\left(D_{11}^{x}+\frac{b_{l}}{E_{s} I_{s}}\right)} \\
& n_{1}=\frac{\left(\frac{h}{2}\right) b_{l}-D_{11}^{x} E_{s} I_{s}\left(\frac{t_{l}}{2}\right)}{D_{11}^{x} E_{s} I_{s}+b_{l}} \\
& n_{2}=\frac{1}{D_{11}^{x} E_{s} I_{s}+b_{l}}
\end{aligned}
$$

Adhesive normal stress general expression can be found by determining the constants $C_{1}$ and $C_{2}$ in Equation (23) with the following boundary conditions.

1st boundary condition: Bending moment at both ends of the laminate equal to zero. Differentiating Equation (18) to the second order and substituting Equations (19, 20 \& $21)$ into the result expression gives the following relationship at laminate end knowing that $M_{l}(0)=0$ gives

$$
\frac{d^{2} \sigma(0)}{d x^{2}}=\frac{E_{a}}{t_{a} E_{s} I_{s}} M_{s}(0)
$$

2nd boundary condition: Shear force at both ends of the laminate equal to zero. Differentiating Equation (18) to the third order and substituting Equations (19) \& (20) into the resulting expression lead to the following relationship at the laminate end knowing that $V_{l}(0)=0$ gives

$$
\frac{d^{3} \sigma(0)}{d x^{3}}=\frac{E_{a}}{t_{a}}\left(\frac{1}{E_{s} I_{s}} V_{s}(0)\right)-n_{3} \tau(0)
$$

Where:

$$
n_{3}=\frac{E_{a}}{t_{a}}\left(\frac{h b_{l}}{2 E_{s} I_{s}}-\frac{t_{l}}{2} D_{11}^{x}\right)
$$

Further differentiation of Equation (23) leads to the second and third derivatives of the interfacial normal stress at the anchorage end. The second and higher order derivatives of q tends to zero. Substituting the boundary conditions into leads to determining $C_{1}$ and $C_{2}$ in terms of the bending moment $M_{s}(0)$ and shear force $V_{s}(0)$ at the end of the CFRP laminate. By substituting the value 
of $M_{s}(0)=P a, V_{s}(0)=P, \tau(0)=-B_{2}, \frac{d^{3} \tau(0)}{d x^{3}}=\lambda^{3} B_{2}$ and $\frac{d^{4} \tau(0)}{d x^{4}}=-\lambda^{4} B_{2} C_{1}$ and $C_{2}$ can be obtained as:

$$
\begin{aligned}
& C_{1}=\frac{P E_{a}}{2 t_{a} \beta^{3} E_{s} I_{s}}[1-\beta a]+\frac{n_{3}}{2 \beta^{3}} B_{2}+\frac{n_{1} B_{2}}{2 \beta^{3}}\left(-\lambda^{4}+\beta \lambda^{3}\right) \\
& C_{2}=\frac{(P a) E_{a}}{2 t_{a} \beta^{2} E_{s} I_{s}}-\frac{n_{1}}{2 \beta^{2}} \lambda^{3} B_{2}
\end{aligned}
$$

With the constants $C_{1}$ and $C_{2}$ determined, the adhesive normal stress can be found using Equation (23).

\subsection{Analysis results}

The results of the peak value of both shear and normal stress for the specimens TB, B3, B4 \& B5 are shown in Table (6). A comparison of the interfacial shear stress for the 3 specimens with similar steel beam cross section B3, B4 \& B5 at $x=0$ and concentrated load of $100 \mathrm{kN}$ is shown in Figure (7). Changing the width of the CFRP plate $b_{k}$ from $100 \mathrm{~mm}$ to $50 \mathrm{~mm}$ increased the stress at the peak point by $75 \%$ at the same prestressing load of $\mathrm{P} 0=25 \mathrm{kN}$.

Table 6. Peak interfacial shear and normal stress for specimen tested.

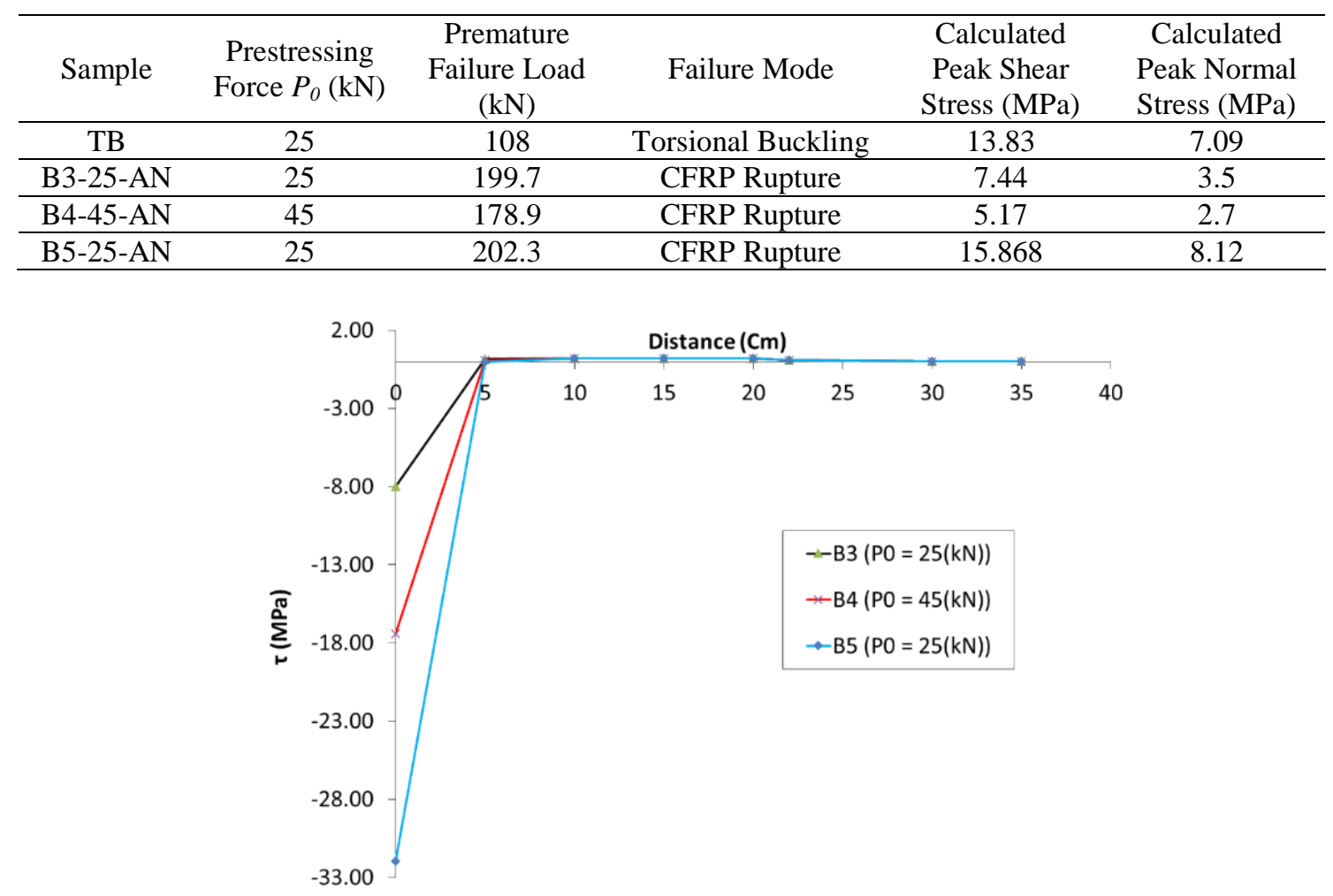

Fig. 7. Adhesive Shear Stress at $P=100 \mathrm{kN}$ and variable distance from laminate end.

\section{CONCLUSIONS}

This study presented the results of an experimental program carried out through nine tests to evaluate the performance of steel beams strengthened by bonded and prestressed CFRP laminate with mechanical end anchorage technique under flexural four point loads an analytical model to predict the shear and normal stress on the adhesive layer. It 
is found that the CFRP prestressing increased the ultimate load of the strengthened beam and moderately delayed the premature debonding failure of the CFRP laminate. It is also concluded that using mechanical end anchorage is essential to maintain the CFRP laminate prestress after releasing the jacking force. It is also concluded that epoxy mortar is not sufficient to maintain the laminate prestressed by itself even at a very low level of prestressing. Although the CFRP prestressing levels of (7\% to $12 \%$ of the ultimate CFRP strength) were moderately low, significant enhancement in the ultimate load of the strengthened beam was recorded. The premature debonding failure was avoided and CFRP laminate were utilized up to their rupture strength. The analytical model results agreed well with the experimental results. Increasing the pretension force from $7 \%$ to $12 \%$ reduced the normal stress affecting the Adhesive layer. The Peak stress point found at the end of the CFRP laminates however the premature failure was observed near the mid span of the beams which implies that the mechanical anchorage prevented the typical debonding failure mode usually occurs for such strengthening technique.

\section{ACKNOWLEDGMENTS}

The authors would like to acknowledge the Civil Engineering Department, King Abdulaziz University for facilitating the experimental program in their laboratory.

\section{PREFERENCES}

[1] Young-Chan Youa, Ki-Sun Choia, and JunHee Kim, 2012. An experimental investigation on flexural behavior of RC beams strengthened with prestressed CFRP strips using a durable anchorage system, Composites Part B, ELSEVIER, 2012; 43:3026-3036.

[2] Miller, T. C., 2000. The rehabilitation of steel bridge girders using advanced composite materials." MSc. Thesis. University of Delaware, Newark, Delaware. USA.

[3] Miller, T.C., Chajes, M.J., Mertz, D.R., and Hastings, J., 2001. Strengthening of a steel bridge girder using CFRP plates. Journal of Bridge Engineering, ASCE, Vol. 6, No. 6, pp. 514-522.

[4] Young-Chan Y. A., Choi A. K., and Kim J. A., "An experimental investigation on flexural behavior of RC beams strengthened with prestressed CFRP strips using a durable anchorage system". Composites. Part B, Engineering, ELSEVIER. 2012; 43: 3026-3036.

[5] Lam, D. and Clark, K.A., 2003. Strengthening of steel sections using carbon fibre reinforced polymers laminate," Proceedings, Advances in Structures: Steel, Concrete, Composite and Aluminum ASSCCA'03, Sydney, Australia, pp. 1369-1374.

[6] Ghareeb, M.A, Khadr, M.A., Sayed-Ahmed, E.Y. CFRP Strengthening of Steel IBeam against Local Web Buckling: a Numerical Analysis. Research and Applications in Structural Engineering, Mechanics \& Computation: Proceedings of the Fifth International Conference on Structural Engineering, Mechanics \& Computation, A. Zingoni (ed.), Taylor \& Francis Group Ltd, Cape Town, South Africa, 2-4 Sept. 2013.

[7] Smith S., Teng J., (2001) "Interfacial stresses in plated beams". Journal of Engineering Structures, ELSEVIER. 2001; 23: 857-871.

[8] Abdelrazik, A, Strengthening of steel I section Beam-Column using Prestressed CFRP Laminates, MSc. Thesis, Ain Shams University Faculty of Engineering, 2013, 154p.

[9] Youssef M. "Analytical prediction of the linear and nonlinear behaviour of steel beams rehabilitated using FRP sheets". Journal of Engineering Structures, ELSEVIER. 2006; 28:903-911.

[10] Benachour A, Benyoucef S, Tounsi A, Adda bedia E. Inter-facial stress analysis of steel beams reinforced with bonded prestressed FRP plate. Journal of Engineering Structures, ELSEVIER. 2008; 30:3305-3315. 
[11] Sayed-Ahmed, E.Y. 2006. Numerical Investigation into Strengthening Steel ISection Beams Using CFRP Strips. Proceedings, 2006 Structures Congress, ASCE, St. Louis, USA, 18-20 May 2006.

[12] Sayed-Ahmed, E.Y. 2004. Strengthening of Thin-Walled Steel I-Section Beams Using CFRP Strips. Proceedings, 4th International Conference on Advanced Composite Materials in Bridges and Structures (ACMBS IV), Calgary, Alberta, Canada - CD Proceedings.

[13] D. Linghoff, M. Al-Emrani and R. Kliger, (2010) " Performance of steel beams strengthened with CFRP laminate - Part 1: laboratory tests" Composites Part B: Engineering, Vol. 41, No.7, p 509-515.

[14] D. Linghoff, M. Al-Emrani and R. Kliger, (2010) " Performance of steel beams strengthened with CFRP laminate - Part 2: FE analyses" Composites Part B: Engineering, Vol. 41, No.7, p 516-522.

[15] Al-Emrani M, Kliger R. Analysis of interfacial shear stresses in beams strengthened with bonded prestressed laminates. Journal of Composites Part B: Engineering, ELSEVIER. 2006; 37:265-272. 